\title{
How Do We Live Together During a Lockdown in Belgium? Study of Couple and Parental Satisfaction
}

\author{
Sarah Galdiolo ${ }^{1}$ (D) Marie Géonet ${ }^{2} \cdot$ Justine Gaugue $^{1}$
}

Accepted: 19 January 2022

(c) Associação Brasileira de Psicologia 2022

\begin{abstract}
In March 2020, the disease caused by SARS-CoV-2 coronavirus was declared a pandemic by the World Health Organization. To reduce the risk of infection, Belgian government ordered restrictive isolation measures. If lockdown and social isolation have proven to be quite effective in terms of physical health, little is known about the impact of the lockdown on couple and parental satisfaction. The current study concerned the first wave of a 5-wave longitudinal research programme relative to the trajectory of couple and parental satisfaction around the lockdown $(N=779$ individuals) on 3 cohorts based on the government announcements (i.e. beginning of the lockdown and subsequent extended lockdowns). The objective was to compare the level of couple and parental satisfaction during the strict first lockdown in Belgium with normative values, considering any gender, parenting, and cohabitation differences. Participants were invited to complete four scales of the Marital Satisfaction Inventory Revised, i.e. Global Distress, Difficulties in Problem-solving Communication, Aggression, and Conflicts over Children Rearing. Two main findings emerged from the study. First, our results showed more couple satisfaction during the lockdown, in comparison to normative situations. During the lockdown, partners expressed more general couple satisfaction. They also felt more effective in resolving couple conflicts and in problem-solving communication and they experienced less couple physical and verbal aggression. Second, higher levels of conflicts over children rearing between partners during the lockdown were observed, in comparison to normative situations. However, major gender differences were observed: While mothers assessed more parental conflicts during the lockdown in comparison to normative situations, fathers reported less conflicts. Finally, our results showed gender differences in parental satisfaction between the three cohorts: Mothers expressed more parental conflicts over children rearing after the first extension of the lockdown in comparison to the beginning of the lockdown while no differences
\end{abstract}

The current manuscript is an original work, not previously published, and not under consideration elsewhere.

Extended author information available on the last page of the article 
were observed in fathers. The discussion highlighted the positive aspects of lockdown for couples and the gender differences relative to the satisfaction over children rearing.

Keywords Couple satisfaction · Parental satisfaction · COVID-19 · Lockdown · Gender differences

In March 2020, the disease caused by SARS-CoV-2 coronavirus has been declared a "pandemic" by the World Health Organization. To reduce the risk of contamination, Belgian government has ordered restrictive isolation measures, e.g. homeworking, closed schools and day care facilities, and homestay. Four successive governmental announcements relative to the lockdown were made. March 17th was the beginning of the lockdown, especially the closure of schools, day care facilities, universities, restaurants, bars, and non-food stores, and homeworking for many people (except for the front-line professions). The lockdown was announced to last until April 5th. On March 27th, following a National Security Council, politicians and health experts decided to extend the lockdown until April 19th. On April 15th, the Prime Minister announced the extension of the lockdown until May 3rd. During this restrictive lockdown, Belgian citizens could only have contacts with people living with them. On May 4th, Belgium has progressively and slowly begun to get out from this strict lockdown. Since June 8th, Belgian citizens experienced semi-lockdowns (i.e. homeworking but shops and schools are opened).

Many studies and reviews have been made on the psychological impact of the lockdown on individuals. Most reviewed studies (for details, see Brooks et al., 2020) reported negative psychological individual effects such as post-traumatic stress symptoms, confusion, anger, anxiety, and depressive symptoms, especially when lockdown lasts more than 10 days with no clear time limit or subsequent extensions of the lockdown. Change in sleep patterns was also observed during the lockdown (Cellini et al., 2020) with sleep difficulties and low sleep quality associated with higher levels of depression, anxiety, and stress symptoms. Data from Google trends were analysed (Brodeur et al., 2020), showing a substantial increase in the search intensity for boredom, loneliness, worry, and sadness. In Belgium, a large study (Lorant \& Van den Broeck, 2020) with two-time measurements has been made, i.e. on March 21st (beginning of the lockdown) and on April 21st (second extension of the lockdown). At the first wave of data collection, 52\% of participants were psychologically distressed and showed high levels of acute stress and anxiety, especially women and young people (15-25 years old). At the second wave of data collection, $49 \%$ of participants were psychologically distressed but the symptoms were clearly different, i.e. lower levels of acute stress and anxiety but higher levels of sleep difficulties (e.g. insomnia), poor concentration, loss of self-confident, and lower levels of self-esteem. High identical levels of depressive symptoms were observed in the two waves of data collection. The factors associated with psychological distress and feelings of loneliness were (a) change in working conditions (i.e. homeworking or cessation of work) and (b) the decrease in social activities. 
Despite a large interest in the psychological experience of the lockdown relative to the SARS-CoV-2 coronavirus, very few studies have been realized on the influence of the lockdown on couple and parental relationships. Yet, engaging in a romantic and parental relationship is one of the most important life experiences in adulthood. Satisfying intimate and parental relationships are important predictors of many aspects of one's life, such as life satisfaction (Be et al., 2013), psychological and physical health (Whisman \& Uebelacker, 2006), social and professional life, or even children's behavioural and emotional development (O'Leary \& Vidair, 2005). This pandemic has profoundly affected couples' daily lives and created multiple daily challenges. One important challenge has been maintaining well-functioning intimate relationships. Research on couple satisfaction showed that external stressors (e.g. economic difficulties, demanding jobs, or disasters) can threaten the quality and stability of couples' relationships (Karney \& Bradbury, 1995). Yet couple and parental satisfaction and relationship can directly and indirectly influence each partner's (and their children's) physical and mental well-being (Loving \& Slatcher, 2013). As such, couple and parental distress has a strong linkage to emotional, behavioural, and health problems in adult partners and their offspring (Snyder et al., 2005). So, the influence of the lockdown on the couple and parental relationship seems to be of great importance for social and health policies and needs to be examined.

Currently, two convincing pictures of how lockdown affects (parental) couples' lives could be painted: one with tensions over childcare and household tasks, threats of divorce, and even domestic violence, and one with an increase in intimacy and even a risk of baby boom. On one side, the lockdown would lead to an increase in couples' conflicts and in shared childcare and household tasks in parental couples (Biroli et al., 2020). Previous studies (Glowacz et al., 2021; Luetke et al., 2020) reported greater couples' conflicts, sexual difficulties, and physical and psychological violence since the spread of COVID-19 pandemic. Gender differences were observed, with an increase in relational stress and in burden especially on women (Schokkenbroek et al., 2021), which created tensions in couples over the division of household and childcare tasks. As such, men tended to do more grocery shopping while women tended to do more all the other household tasks. Biroli et al. (2020) suggested that some factors relative to Western gender norms would play in the men's tendency to do more shopping, i.e. risk perceptions, the unskilled nature of the task, and the vision of men as hunters or connectors between the domestic and public sphere. The increase in sharing childcare was also gender specific: Mothers were more involved in the supervision of children's homework while men more in playing with children (Carlson et al., 2020). This gender-specific context increased the tensions over the division of household tasks, leading to more anxiety and less well-being especially by women (Schokkenbroek et al., 2021). Moreover, the frequently blurred boundary between work and homelife provided new opportunities for couple's conflict, as do the intensification of parenting roles and prevalence of other stressors, such as unemployment or income reduction (Lebow, 2020). All these tensions about parenting roles, shared household tasks, and work-related stress could make for a hothouse of interaction during a moment in which there are limited possibilities for escape into the outside world. In parallel, social interactions 
and support that might mitigate tensions were decreased. As such, in the context of lockdown, couples risked to fall into angry exchanges without resolution or into patterns of demand-withdrawal, which may degenerate into protracted high conflicts, sometimes separation or divorce, and even domestic violence (Glowacz et al., 2021; Kellam, 2020; Lebow, 2020).

On the other side, a study on Google trends (Brodeur et al., 2020) reported a decrease in the search intensity for divorce. The intense environment that has emerged the wake of COVID-19 would have led many couples to greater intimacy, egalitarianism, and connection (Günther-Bel et al., 2020; Stanley \& Markman, 2020). Alon et al. (2020) suggested that gender differences relative to childcare could decrease during the lockdown, with long-run effects. Hence, even if on average women would shoulder most of the increase in childcare responsibilities, many fathers would have experienced a large increase in their childcare hours too (Yerkes et al., 2020). It would be likely that this high exposure would have at least some persistent effect on future contributions to childcare be it through learning by doing, more information about what kids are actually doing all day, or through increased attachment to children (Alon et al., 2020). This situation would lead to less tensions in parental couples. Thus, these previous studies were essentially speculative and gave two opposite results: The lockdown would lead (parental) couples towards (a) a greater gender gap relative to household and childcare tasks and more parental/ couple difficulties vs. (b) more egalitarianism, shared household, and childcare tasks and then less parental/couple difficulties.

The current study concerned the first wave of a 5-wave longitudinal research programme relative to the changes of couple and parental satisfaction during a strict lockdown, on three cohorts based on the government announcements (i.e. March 17th, March 27th, and April 15th, respectively the beginning of the lockdown and subsequent extended lockdowns). The objective was to compare the level of couple and parental satisfaction in lockdown situation to normative situations (i.e. no lockdown situations). More specifically, three main couples' areas were investigated, i.e. (a) global distress (i.e. general dissatisfaction with the couple relationship), (b) difficulties in problem-solving communication (i.e. couple's ineffectiveness for resolving conflicts), and (c) aggression (i.e. physical and verbal aggression experienced by the partner). One parental area was investigated, i.e. conflicts over children rearing (i.e. conflicts between partners relative to children's rearing). Previous studies (e.g. Günther-Bel et al., 2020) underlined differences in couple satisfaction and relationship during the lockdown, in comparison to normative situations, but differed in the direction of this difference (i.e. less couple satisfaction vs. more couple satisfaction during the lockdown). Some studies associated more couple satisfaction with more shared household between men and women (e.g. Alon et al., 2020), while other studies associated less couple satisfaction with more gender differences in household (e.g. Schokkenbroek et al., 2021). Consequently, we hypothesized that the level of couple and parental satisfaction was different during the lockdown, in comparison to normative situations, but the direction of this difference and the question of gender differences remained exploratory. Second, Brooks et al. (2020) reported negative psychological effects of the lockdown, especially when lockdown lasts more than 10 days with no clear time limit or subsequent extensions of the lockdown. 
Consequently, we expected weaker levels of couple and parental satisfaction after the second and third government announcements. Third, because of the intensification of parental roles and burden, we expected weaker levels of couple and parental satisfaction for parents in lockdown, in comparison to non-parents and normative situations. The number of children was also included as a factor of influence on couple and parental satisfaction. We hypothesized that the number of children would increase the burden, which would lead to more couple and parental dissatisfaction. Finally, previous research showed lower levels of couple satisfaction for non-cohabiting couples than cohabiting couples (Gatzeva \& Paik, 2011; Willoughby et al., 2011). The COVID-19 pandemic and lockdown led to difficulties for non-cohabiting partners to meet each other. Consequently, we expected lower levels of couple satisfaction for non-cohabiting partners.

\section{Method}

\section{Participants and Procedure}

Data were collected from a sample of 779 individuals $(N=195$ men and $N=583$ women) who were in a relationship ( $M=16.58$ years, $S D=10.31$ years). The participants' ages ranged from 18 to 78 years old $(M=36.09, S D=11.59$ for the overall sample; $M=37.43, S D=12.69$; and $M=35.65, S D=11.19$, for men and women respectively). Many participants lived with their partner $(N=688)$. In total, 306 participants were parents. During the lockdown, the participants spent a large amount of their time with their partner $(M=18.42 \mathrm{~h}, S D=7.49 \mathrm{~h})$. Participants were recruited via social networks. The questionnaire was completed online via Lime Survey $3.0+$. To participate, participants should be 18 years old minimum and be in a romantic relationship. Sociodemographic information and information about the specific lockdown context are presented in Table 1.

\section{Measures}

Couple Satisfaction Couple satisfaction was assessed by means of a French version of the Marital Satisfaction Inventory Revised (MSI-R) (Brodard et al., 2015). This questionnaire consisted of 13 scales, i.e. Conventionalization, Global Distress, Affective Communication, Difficulties in Problem-solving Communication, Aggression, Time Together, Disagreement about Finances, Sexual Dissatisfaction, Role Orientation, Family History of Distress, Dissatisfaction with Children, Conflict over Children Rearing, and Consistency. Because of the risk of high attrition, only four scales were used in the current study, i.e. Global Distress (general dissatisfaction with the couple relationship, 22 items), Difficulties in Problem-solving Communication (couple's ineffectiveness for resolving conflicts, 19 items), Aggression (physical and verbal aggression experienced by the partner, 10 items), and Conflicts over Children Rearing (conflicts between partners relative to children's rearing, 10 items). These specific 4 scales were selected because of their non-stable 
Table 1 Sociodemographic information and information about the specific lockdown context

\begin{tabular}{|c|c|c|}
\hline & Frequency & Percent \\
\hline \multicolumn{3}{|l|}{ Employment status } \\
\hline Homeworking & 449 & 57.6 \\
\hline At the workplace & 60 & 7.7 \\
\hline No work & 215 & 27.6 \\
\hline Part-time at the workplace & 55 & 7 \\
\hline \multicolumn{3}{|l|}{ Housing size } \\
\hline Less than $60 \mathrm{~m}^{2}$ & 45 & 5.7 \\
\hline $60-100 \mathrm{~m}^{2}$ & 154 & 19.8 \\
\hline $100-140 \mathrm{~m}^{2}$ & 220 & 28.2 \\
\hline $140-180 \mathrm{~m}^{2}$ & 185 & 23.7 \\
\hline More than $180 \mathrm{~m}^{2}$ & 175 & 22.5 \\
\hline \multicolumn{3}{|l|}{ Access to the outside world } \\
\hline Terrace and garden & 245 & 31.5 \\
\hline Stroll in the neighbourhood & 79 & 10.1 \\
\hline No access & 13 & 1.7 \\
\hline $\begin{array}{l}\text { Terrace/garden and stroll in the } \\
\text { neighbourhood }\end{array}$ & 442 & 56.7 \\
\hline \multicolumn{3}{|l|}{ Number of children } \\
\hline 1 & 128 & 16.4 \\
\hline 2 & 215 & 27.6 \\
\hline 3 & 96 & 12.3 \\
\hline 4 & 20 & 2.6 \\
\hline 5 and more & 12 & 1.6 \\
\hline
\end{tabular}

characteristics, which are needed to consider when studying major life events such as COVID-19 pandemic. For each item, participants were asked to indicate whether the affirmation was true (1) or false (0). A sum of the items was made for each scale, with higher scores indicating greater relationship distress. The MSI-R has shown high Cronbach's alphas $(\alpha \mathrm{s}>0.70)$ and hence was considered to be highly reliable with high construct, predictive, and convergent/discriminant validity (Brodard et al., 2015). In our sample, $\alpha$ s varied between 0.70 and 0.96 for the different scales.

\section{Results}

Descriptive Statistics Table 2 refers to the descriptive statistics relative to the four selected scales of MSI-R. Statistical analyses were also conducted separately according to (a) gender, (b) parenting, and (c) cohabitation or not with the partner. Values for the Total Sample and Post Hoc Tests for Government Announcements The 
Table 2 Descriptive statistics for MSI-R

\begin{tabular}{|c|c|c|c|c|c|c|c|c|c|c|c|c|c|c|}
\hline & \multirow{2}{*}{\multicolumn{2}{|c|}{$\begin{array}{l}\text { Total } \\
\text { sample }\end{array}$}} & \multicolumn{4}{|c|}{ Gender } & \multicolumn{4}{|c|}{ Children } & \multicolumn{4}{|c|}{ Cohabitation } \\
\hline & & & \multicolumn{2}{|c|}{ Women } & \multicolumn{2}{|l|}{ Men } & \multicolumn{2}{|c|}{ No children } & \multicolumn{2}{|c|}{ Children } & \multicolumn{2}{|c|}{$\begin{array}{l}\text { No cohabi- } \\
\text { tation }\end{array}$} & \multicolumn{2}{|c|}{$\begin{array}{l}\text { Cohabita- } \\
\text { tion }\end{array}$} \\
\hline & $M$ & $S D$ & $M$ & $S D$ & $M$ & $S D$ & $M$ & $S D$ & $M$ & $S D$ & $M$ & $S D$ & $M$ & $S D$ \\
\hline GD & 2.88 & 4.65 & 3.19 & 4.99 & 1.95 & 3.29 & 2.12 & 3.80 & 3.37 & 5.06 & 3.43 & 4.80 & 2.81 & 4.62 \\
\hline PSC & 4.74 & 4.38 & 4.96 & 4.58 & 4.06 & 3.66 & 4.09 & 4.00 & 5.16 & 4.56 & 4.86 & 4.87 & 4.72 & 4.32 \\
\hline AGG & 0.95 & 1.25 & 0.95 & 1.27 & 0.97 & 1.17 & 0.86 & 1.13 & 1.01 & 1.31 & 1.00 & 1.10 & 0.95 & 1.27 \\
\hline CCR & 1.87 & 2.36 & 2.20 & 2.56 & 0.83 & 1.08 & & & & & 2.25 & 3.02 & 1.86 & 2.34 \\
\hline
\end{tabular}

$G D$ global distress, $P S C$ problem-resolving communication, $A G G$ aggression, $C C R$ conflicts over child rearing, $n=779$ individuals

couple and parental satisfaction during the lockdown was compared with normative values (Brodard et al., 2015). $t$-tests showed that Global Distress $[t(767)=-7.50$, $p=0.00]$, Difficulties in Problem-solving Communication $[t(768)=-5.44$, $p=0.00]$, and Aggression [t(768) $=-20.68, p=0.00]$ were lower and that Conflicts over Children Rearing $[t(337)=2.49, p=0.01]$ were higher during the lockdown when the total sample was considered. Post hoc tests showed significant differences between the first (i.e. March 18th as the beginning of the lockdown) and the second (i.e. March 27th as the first extension of the lockdown) government announcements for Conflicts over Children Rearing $[F(2,390)=3.49, p=0.03]$ with higher scores after the second announcement.

\section{Couple and Parental Satisfaction Comparisons Between Lockdown and Norma- tive Values for Women and Men Separately and Post Hoc Tests for Government} Announcements The men's and women's couple and parental satisfaction during the lockdown was compared with men's and women's normative values (Brodard et al., 2015). Considering men, $t$-tests showed that Global Distress $[t(192)=-7.55$, $p=0.00]$, Difficulties in Problem-solving Communication $[t(192)=-5.91$, $p=0.00]$, Aggression $[t(192)=-8.82, p=0.00]$, and Conflicts over Children Rearing $[t(81)=-4.81, p=0.00]$ were lower during the lockdown. Considering women, $t$-tests showed that Global Distress $[t(573)=-6.44, p=0.00]$, Difficulties in Problem-solving Communication $[t(574)=-3.25, p=0.00]$, and Aggression $[t(574)=-5.99, p=0.00]$ were lower and that Conflicts over Children Rearing $[t(255)=3.08, p=0.00]$ were higher during lockdown. Next, we compared women's and men's couple satisfaction during lockdown. $t$-tests showed that women perceived higher Global Distress [ $\left.t(503.56)=-3.92, p=0.00, \eta^{2}=0.02\right]$, Difficulties in Problem-solving Communication $\left[t(408.56)=-2.76, p=0.01, \eta^{2}=0.01\right]$, and Conflicts over Children Rearing $\left[t(313.83)=-6.89, p=0.00, \eta^{2}=0.06\right]$ than men during the lockdown. Effect sizes were small for Global Distress and Difficulties in Problem-solving Communication while moderate for Conflicts over Children Rearing. Aggression $[t(766)=0.27, p=0.80]$ was assessed similarly by women and men. Post hoc tests showed significant differences between the first (i.e. March 18th as the 
beginning of the lockdown) and the second (i.e. March 27th as the first extension of the lockdown) government announcements, only for women with higher scores on Global Distress $[F(2,573)=4.44, p=0.01]$ and Conflicts over Children Rearing $[F(2,255)=3.31, p=0.04]$ after the second announcement.

Couple Satisfaction Comparisons Between Lockdown and Normative Values for Parents and Non-parents t-tests showed that Global Distress, Difficulties in Problemsolving Communication, and Aggression were lower during the lockdown for parents $[t(464)=-3.25, p=0.00 ; t(465)=-2.08, p=0.04 ; t(465)=-14.29, p=0.00$, for Global Distress, Difficulties in Problem-solving Communication, and Aggression respectively] and non-parents $[t(302)=-9.24, p=0.00 ; t(302)=-6.55$, $p=0.00 ; t(465)=-15.72, p=0.00$, for Global Distress, Difficulties in Problemsolving Communication, and Aggression respectively], in comparison to normative values. Next, we compared parents and non-parents during the lockdown. $t$-tests showed that parents perceived higher Global Distress $[t(750.89)=-3.91, p=0.00$, $\left.\eta^{2}=0.02\right]$ and Difficulties in Problem-solving Communication $[t(701.66)=-3.42$, $\left.p=0.00, \eta^{2}=0.02\right]$ than non-parents while Aggression $[t(767)=-1.67, p=0.09]$ was similarly assessed between parents and non-parents. However, effect sizes were quite small.

Couple Satisfaction Comparisons Between Lockdown and Normative Values for Cohabiting vs. Non-cohabiting Couples $t$-tests showed that Global Distress, Difficulties in Problem-solving Communication, and Aggression were lower during the lockdown for cohabiting couples $[t(679)=-7.50, p=0.00 ; t(680)=-5.29$, $p=0.00 ; t(680)=-19.31, p=0.00$, for Global Distress, Difficulties in Problemsolving Communication, and Aggression respectively] while only Aggression was lower during the lockdown for non-cohabiting couples $[t(87)=-1.38, p=0.17$; $t(87)=-1.42, p=0.16 ; t(87)=-7.52, p=0.00$, for Global Distress, Difficulties in Problem-solving Communication, and Aggression respectively]. Now, when comparing cohabiting and non-cohabiting couples, $t$-tests did not show any differences $[t(766)=1.19, p=0.24 ; t(767)=0.28, p=0.78 ; t(767)=0.36, p=0.72$, for Global Distress, Difficulties in Problem-solving Communication, and Aggression respectively].

Influence of the Number of Children on Couple and Parental Satisfaction Linear regressions have been made to analyse the influence of the number of children on couple and parental satisfaction. Results showed that the number of children did not influence Global Distress $(\beta=0.03, p=0.47)$, Difficulties in Problem-solving Communication $(\beta=0.05, p=0.26)$, and Aggression $(\beta=0.04, p=0.44)$ while positively Conflicts over Children Rearing $(\beta=0.35, p=0.01)$. When comparing women and men, linear regressions showed a positive impact of the number of children on Conflicts over Children Rearing for women $(\beta=0.21, p=0.00)$ but no impact for men $(\beta=0.06, p=0.56)$. 


\section{Discussion}

The main purpose of the current study was to compare the level of couple and parental satisfaction during a strict lockdown to normative situations (i.e. no lockdown situations), by considering gender differences, parenting, the number of children, and cohabitation. Two main findings emerged from the study. First, our results showed more couple satisfaction during the lockdown, in comparison to normative situations. Men seemed more satisfied than women but (a) the gender differences effects were quite small and (b) there were also gender differences in normative situations. Thus, during the lockdown, partners expressed more general couple satisfaction. They also felt more effective in resolving couple conflicts and in problem-solving communication. They also experienced less couple physical and verbal aggression. Our results did not show any influence of whether or not you are a parent or live together and the number of children on couple satisfaction during the lockdown. How could such results be explained? Two possible explanations could be made. First, the lockdown may have led the partners to share and to regulate more their personal emotions within the couple rather than friends or large family. Thus, couple's sharing and regulation of emotions could initiate support and contribute to higher togetherness (Rohr et al., 2019). Second, there is evidence that couples' shared time is important for both couple quality (e.g. Gager \& Sanchez, 2003; Hallberg, 2003; Hamermesh, 2000) and individual enjoyment and happiness (Flood \& Genadek, 2016). The amount of time partners spend together would be positively associated with enhanced experienced couple well-being (Genadek et al., 2019). Research also showed that many people feel they usually do not have enough time with their partners and would like to spend more time with them (Nomaguchi et al., 2005; Roxburgh, 2006). Moreover, time together might be a valuable resource to help partners buffer the negative effects of stress (Randall \& Bodenmann, 2009): Partners are better able to adapt to and cope with stress. During the lockdown, partners tended to spend a large amount of time together (18 h and $42 \mathrm{~min}$ on average) because of teleworking and less social and family meetings, which could lead to better stress coping, more individual and couple well-being, and then more couple satisfaction.

Our results did not show any influence of whether or not you are a parent and the number of children on couple satisfaction during the lockdown, which disconfirmed our hypothesis related to the additional burden of children on couple satisfaction. One hypothesis to explain this result could be that the benefits for the couple related to this first strict lockdown would be higher than the costs, even for parents. Again, sharing time together allowed better manage daily stress (Randall \& Bodenmann, 2009), whatever or not you are a parent and the number of children you have. Moreover, our study considered three cohorts relative to the three first government announcements. Our results did not show any differences in couple satisfaction between the three cohorts. Now, when considering gender differences, higher levels of couple global distress were observed in women after the second announcement (i.e. the first extension of the lockdown) in comparison to the first announcement (i.e. the beginning of the lockdown). No such results were 
found for men. It would appear that women could more suffer from the extension of the lockdown than men, which could lead to more couple distress in women.

Second, our study also focused on parental satisfaction, especially conflicts over children rearing. Items for assessing Conflicts over Children Rearing referred to (a) the agreement between both partners over children rearing (e.g. My partner and I set together the educational rules) and (b) the partner's ability to meet his or her parenting responsibilities (e.g. My partner does not take responsibility for our children). When comparing to normative situations, our results showed that there were more conflicts over children rearing during the lockdown. However, major gender differences were observed: While mothers assessed more parental conflicts during the lockdown in comparison to normative situations, fathers reported less conflicts. Moreover, the number of children had a positive influence on the variable "Conflicts over Children Rearing" only for mothers: The more children there were, the more mothers assessed higher levels of conflicts. Our results also showed gender differences in parental satisfaction between the three cohorts: Mothers expressed more parental conflicts over children rearing after the second government announcement (i.e. the first extension of the lockdown) in comparison to the first government announcement (i.e. the beginning of the lockdown) while no differences were observed in fathers. How could such results be explained? Previous research (e.g. Baxter et al., 2008) has already shown that the transition to parenthood were critical moments in the development of an unequal gap in time spent on routine childcare labour. Having additional children would continue to increase women's time on childcare and housework while men would tend to spend less time doing housework and childcare when higher-order births occurred. Therefore, three possible explanations could be made for explaining our results. First, during the lockdown, the unequal gender gap may have grown, which would lead to an increase in mother's housework and childcare and therefore a greater parental dissatisfaction. Second, the lockdown would lead to an increase in household and childcare for both partners (Biroli et al., 2020), without creating a larger gender gap than usual. However, the daily lockdown would lead mothers to realize that their partner usually does fewer tasks than they do. This would be an awareness of the daily maintaining gender gap in household and childcare. Third, if mothers usually spend more time in childcare, it means that they were also more often alone to make decisions for children rearing. During the lockdown, both partners were physically present and could thus be responsible for children rearing, which could create interference between both partners and thus parental conflicts. For mothers, it could be more difficult to manage with their partner about children rearing when they were used to taking care of them on their own.

Finally, Brooks et al. (2020) reported negative psychological effects of the lockdown, especially when lockdown lasts more than 10 days with no clear time limit or subsequent extensions of the lockdown. Our results partially confirmed Brooks et al.'s study. The first extension of the lockdown negatively influenced women's couple and parental satisfaction, with higher levels of couple distress and parental conflicts over children rearing. Such results were not found for men. Thus, the extensions of the lockdown would appear to be particularly difficult for women. Why? We could ask whether the uncertainty about the duration and the outcomes of the 
lockdown were particularly exhausting for women who may fear an increase of the family burden.

\section{General Conclusion, Research and Practical Highlights, and Limitations}

The current study was the first one to investigate the influence of the lockdown on couple and parental satisfaction. Different pictures were defined. First, couple satisfaction would be higher during the lockdown, in comparison to normative situations for two potential reasons, i.e. the time spent together or couple's sharing and regulation of emotions. Second, gender differences appeared for parental satisfaction during the lockdown: While mothers assessed more parental conflicts during the lockdown in comparison to normative situations, fathers reported less conflicts.

The first limitation of the study was related to the sample size. The questionnaire included many items, which may have discouraged many participants. Moreover, participants were recruited via social networks, which could lead to a selection bias through the exclusion of more vulnerable population groups (i.e. digital gap). The second limitation referred to the trajectory of couple and parental satisfaction during the lockdown. Does the couple satisfaction maintain at higher levels? Does the parental satisfaction stay different between mothers and fathers? Third, it would be interesting to investigate more (co-)parenting domains during the lockdown to better understand the gender gap and the parental reality, e.g. coparenting agreement, coparenting closeness, exposure of child to conflict, coparenting support, coparenting undermining, endorsement of partner's parenting, and division of labour (Feinberg et al., 2012). Fourth, our study did not include data on children's age while the intensification of parental roles and burden are clearly related to the children's age and development. Finally, our results underlined that women experienced higher levels of conflicts related to children rearing while being more satisfied with their couple relationship during the lockdown, in comparison to normative situations. We wondered if the amount of time shared together (i.e. in the family vs. couple) could be a mechanism that explains this difference between parental and couple satisfaction. As mentioned earlier, while the amount of time shared together could be a positive characteristic of the lockdown to increase couple satisfaction, it could lead to more parental dissatisfaction in women for different potential reasons, i.e. unequal gender gap or parental interferences related to children rearing. Further studies should include these limitations in their methodological design.

Currently, the pandemic is still going on. We are not unlocked and there are obvious risks to be again in a restrictive lockdown. Such risks lead people to feelings of uncertainty, anxiety, and loss of freedom. Now, our study showed nuanced results on couple and parental satisfaction. To our opinions, we should keep in mind the following aspects. Our results underlined some positive aspects of the lockdown, especially less couple distress, couple aggression, and greater resolution of conflicts. When possible, couples could take advantage of the lockdown to increase intimacy and sharing of emotions within the couple. Now, the women's parental dissatisfaction should be seriously considered. Lorant and Van den Broeck (2020) have showed 
that women especially psychologically suffered during the lockdown. There is an urgent need to be vigilant about women's burden and finally to ensure gender equality for household and childcare tasks. Such a message should be heard by women and men, businesses, employers, and the society.

Data Availability The datasets generated during and/or analysed during the current study are available from the corresponding author on reasonable request.

\section{Declarations}

Ethical approval The authors have complied with the American Psychology Association's ethical standards in the treatment of their sample.

Informed Consent Informed consent was obtained from all individual participants included in the study.

Conflict of Interest The authors declare no competing interests.

\section{References}

Alon, T. M., Doepke, M., Olmstead-Rumsey, J., \& Tertilt, M. (2020). The impact of Covid-19 on gender equality. NBER Working Paper Series, 26947.

Baxter, J., Hewitt, B., \& Haynes, M. (2008). Life course transitions and housework: Marriage, parenthood, and time on housework. Journal of Marriage and Family, 70(2), 259-272. https://doi.org/10.1111/j. 1741-3737.2008.00479.x.

Be, D., Whisman, M. A., \& Uebelacker, L. A. (2013). Prospective associations between marital adjustment and life satisfaction. Personal Relationships, 20, 728-739. https://doi.org/10.1111/pere.12011.

Biroli, P., Bosworth, S., Della Giusta, M., Di Girolamo, A., Jaworska, S., \& Vollen, J. (2020). Family life in lockdown. Working Paper.

Brodard, F., Charvoz, L., Antonietti, J.-P., Rossier, J., Bodenmann, G., \& Snyder, D. K. (2015). Validation de la version française de l'Inventaire de satisfaction conjugale MSI-R. Canadian Journal of Behavioural Science, 47(1), 113-122. https://doi.org/10.1037/a0037589.

Brodeur, A., Clark, A. E., Flèche, S., \& Powdthavee, N. (2020). Covid-19, lockdowns, and well-being: Evidence from Google trends. Discussion Paper Series.

Brooks, S. K., Webster, R. K., Smith, L. E., Woodland, L., Wessely, S., Greenberg, N., \& Rubin, G. J. (2020). The psychological impact of quarantine and how to reduce it: Rapid review of the evidence. The Lancet, 395, 912-920. https://doi.org/10.1016/S0140-6736(20)30460-8.

Carlson, D., Petts, R., \& Pepin, J. (2020). US couples' divisions of housework and childcare during Covid-19 pandemic. https://doi.org/10.31235/osf.io/jy8fn.

Cellini, N., Canale, N., Mioni, G., \& Costa, S. (2020). Changes in sleep pattern, sense of time, and digital media use during Covid-19 lockdown in Italy. Journal of Sleep Research, 29(4), 1-5. https://doi.org/10. $1111 /$ jsr.13074.

Feinberg, M. E., Brown, L. D., \& Kan, M. L. (2012). A multi-domain self-report measure of coparenting. Parenting: Science and Practice, 12(1), 1-21. https://doi.org/10.1080/15295192.2012.638870.

Flood, S. M., \& Genadek, K. R. (2016). Time for each other: Work and family constraints among couples. Journal of Marriage and Family, 78(1), 142-164. https://doi.org/10.1111/jomf.12255.

Gager, C. T., \& Sanchez, L. (2003). Two as one?: Couples' perceptions of time spent together, marital quality, and the risk of divorce. Journal of Family Issues, 24(1), 21-50. https://doi.org/10.1177/01925 $13 \mathrm{X} 02238519$.

Gatzeva, M., \& Paik, A. (2011). Emotional and physical satisfaction in noncohabiting, cohabiting, and marital relationships: The importance of jealous conflict. Journal of Sex Research, 48(1), 29-42. https://doi. org/10.1080/00224490903370602.

Genadek, K. R., Flood, S. M., \& Moen, P. (2019). For better or worse? Couples' time together in encore adulthood. Journals of Gerontology: Social Science, 74(2), 329-338. https://doi.org/10.1093/geronb/ gbx 129.

Glowacz, F., Schmits, E., \& Dziewa, A. (2021). Intimate partner violence and mental health within the community during lockdown of covid-19 pandemic. Manuscript submitted for publication. 
Günther-Bel, C., Vilaregut, A., Carratala, E., Torras-Garat, S., \& Pérez-Testor, C. (2020). A mixed-method study of individual, couple, and parental functioning during the state-regulated COVID-19 lockdown in Spain. Family Process, 59(3), 1060-1079. https://doi.org/10.1111/famp.12585.

Hallberg, D. (2003). Synchronous leisure, jointness, and household labor supply. Labour Economics, 10(2), 185-203. https://doi.org/10.1016/S0927-5371(03)00006-X.

Hamermesh, D. S. (2000). Togetherness: Spouses' synchronous leisure, and the impact of children. Journal of Population Economics, 15(4), 601-623. https://doi.org/10.3386/w7455.

Karney, B. R., \& Bradbury, T. N. (1995). The longitudinal course of marital quality and stability: A review of theory, methods, and research. Psychological Bulletin, 118(1), 3-34. https://doi.org/10.1037/00332909.118.1.3.

Kellam, A. (2020). Domestic abuse during the UK's Covid-19 lockdown: From normal to new normal and what survivors' experiences might teach us. Amicus Curiae, 1(3), 361-378.

Lebow, J. L. (2020). The challenges of Covid-19 for divorcing and post-divorce families. Family Process. https://doi.org/10.1111/famp.12574.

Lorant, V. \& Van den Broeck, K. (2020). Coronavirus containment policies and impact on the population's mental health in Belgium. Manuscript in preparation.

Loving, Y. J., \& Slatcher, R. B. (2013). Romantic relationships and health. In J. A. Simpson \& L. Campbell (Eds.), Oxford library of psychology. The Oxford handbook of close relationships (pp. 617-637). Oxford University Press.

Luetke, M., Hensel, D., Herbenick, D., \& Rosenberg, M. (2020). Romantic relationship conflict due to the COVID-19 pandemic and changes in intimate and sexual behaviors in a nationally representative sample of American adults. Journal of Sex and Marital Therapy, 46(8), 747-762. https://doi.org/10.1080/ 0092623X.2020.1810185.

Nomaguchi, K. M., Milkie, M. A., \& Bianchi, S. M. (2005). Time strains and psychological well-being: Do dual-earner mothers and fathers differ? Journal of Family Issues, 26(6), 756-792. https://doi.org/10. $1177 / 0192513 X 05277524$.

O'Leary, S. G., \& Vidair, H. B. (2005). Marital adjustment, child-rearing disagreements, and overreactive parenting: Predicting child behavior problems. Journal of Family Psychology, 19(2), 208-216. https:// doi.org/10.1037/0893-3200.19.2.208.

Randall, A. K., \& Bodenmann, G. (2009). The role of stress on close relationships and marital satisfaction. Clinical Psychology Review, 29(2), 105-115. https://doi.org/10.1016/j.cpr.2008.10.004.

Rohr, M. K., Nestler, S., \& Kunzmann, U. (2019). A trouble shared is a trouble halved: Age differences in emotional experience and expression during couples' conversations. Psychology and Aging, 34(6), 848-861. https://doi.org/10.1037/pag0000386.

Roxburgh, S. (2006). "I wish we had more time to spend together...": The distribution and predictors of perceived family time pressures among married men and women in the paid labor force. Journal of Family Issues, 27(4), 529-553. https://doi.org/10.1177/0192513X05284008.

Schokkenbroek, J. M., Hardyns, W., Anrijs, S., \& Ponnet, K. (2021). Partners in lockdown: Relationship stress in men and women during the COVID-19 pandemic. Couple and Family Psychology: Research and Practice, 10(3), 149-157. https://doi.org/10.1037/cfp0000172.

Snyder, D. K., Heyman, R. E., \& Haynes, S. N. (2005). Evidence-based approaches to assessing couple distress. Psychological Assessment, 17(3), 288-307. https://doi.org/10.1037/1040-3590.17.3.288.

Stanley, S. M., \& Markman, H. J. (2020). Helping couples in the shadow of Covid-19. Family Process. https://doi.org/10.1111/famp.12575.

Willoughby, B. J., Carroll, J. S., \& Busby, D. M. (2011). The different effects of "living together": Determining and comparing types of cohabiting couples. Journal of Social and Personal Relationships, 29(3), 397-419. https://doi.org/10.1177/0265407511431184.

Whisman, M. A., \& Uebelacker, L. A. (2006). Impairment and distress associated with relationship discord in a national sample of married or cohabiting adults. Journal of Family Psychology, 20(3), 369-377. https://doi.org/10.1037/0893-3200.20.3.369.

Yerkes, M. A., André, S., Beckers, D. G. J., Besamusca, J., Kruyen, P. M., Remery, C., van der Zwan, R., \& Geurts, S. (2020). Intelligent lockdown, intelligent effects? The impact of the Dutch COVID-19 'intelligent lockdown' on gendered work and family dynamics among parents. SocArXiv uq2pf, Center for Open Science. https://doi.org/10.31219/osf.io/uq2pf. 


\section{Authors and Affiliations}

\section{Sarah Galdiolo ${ }^{1}$ (D) Marie Géonet ${ }^{2} \cdot$ Justine Gaugue $^{1}$}

$\triangle$ Sarah Galdiolo

sarah.galdiolo@umons.ac.be

1 Department of Clinical Psychology, University of Mons, 4, ruelle du Cerf Blanc, 7000 Mons, Belgium

2 Institute of Research in Psychological Sciences, University of Louvain, 10, Place du Cardinal Mercier, 1348 Louvain-la-Neuve, Belgium 